\title{
Design and Implementation of Microcontroller Based Programmable Smart Industrial Temperature Control System: An Undergraduate Level Approach
}

\author{
Md Ruhul Amin ${ }^{1}$, Ananda Ghosh ${ }^{2}$ and Abedul Hadi ${ }^{3}$ \\ University of Information Technology and Sciences (UITS), \\ Dhaka-1212, Bangladesh \\ ${ }^{1}$ ruhul.amin@uits.edu.bd, ${ }^{2}$ ananda.ghosh@uits.edu.bd, ${ }^{3}$ abedul.hadi@uits.edu.bd
}

\begin{abstract}
In this paper, a microcontroller with temperature sensor are used to control and monitor temperature smartly. To sense temperature, LM35 temperature sensor is used which works linearly with increase of temperature. Microcontroller compares the asking temperature with real time temperature and passes the instruction to cooling device and heating device to activate or deactivate. The hardware validation shows that the temperature can be maintained between $39^{\circ} \mathrm{C}$ to $41^{\circ} \mathrm{C}$.In addition, a control knob has been used to set temperature according to application having a range of selection choice. A LCD display is used to display both of asking temperature and real time temperature.
\end{abstract}

Keywords: Microcontroller; Temperature; MicroC; Sensor; Control

\section{Introduction}

Several heating and cooling function exist in almost every industry for example textile miles, pharmaceuticals, power station and so on [1]. Smart control of temperature is an important task for smooth running of industries. Each part of industry has particular temperature requirement which is to be acquired during production hour [2]. In [3] defines that in industries, it is very crucial to monitor and control temperature precisely. The effective solution for this problem is to develop a data logger. Earlier it was completed manually using the thermometer and manometer. Since 1990 another progress in data logging took place as people to begin to produce PC based data logging system. A single chip embedded temperature controller design programmed in a single programmable system on chip: mixed array logic consists of analog, digital and digital communication block within in it [4]. The compressed design allows the user to select any type of control function through its computer-generated instrument program. This design can be straight connected to PCs. The web based distributed measurement and control with programmable single-wire digital temperature sensor DS18B20, an embedded system is used as field processing unit. With application mode of $\mathrm{B} / \mathrm{S}$. a remote temperature measurement and control system is designed by embedded in [5]. In case of variable temperature requirement, manufacturing operator can also select multiple options for controlling temperature with displaying necessary information in the display [6]. Number control applications have been already developed in electrical engineering for controlling the automatic system [7]-[8]. Microcontroller can be also used to control light smoothly [9]-[10].

In this paper, PIC 16F876A microcontroller is used to design temperature control system for casting process. For selection of proper temperature, a variable resistance with LM35 sensor [11] is used. This paper is organized as follows: the concept of

Received (January 3, 2018), Review Result (March 10, 2018), Accepted (March 14, 2018) 
temperature control technique is discussed briefly in Section 2. Section 3 consists of precision temperature measurement. Section 4 comprised of design of temperature control circuits where total circuit diagram has be designed using Proteous Labcenter. After that, Section 5 shows results and discussion with experimental results, followed by conclusion has be draw in Section 6 .

\section{Concept of Temperature Control Technique}

To increase the production of an industry, smooth control of temperature is the key function.5 Different industry has its own individual temperature requirement for specific role. Conventionally, industrial temperature measurement instrument thermometer is used to measure the temperature. After observing temperature reading, operator controls temperature manually. Sometimes controlling is not appropriate because of time consuming human operated control of cooling device and heating device. As a result, efficiency of temperature control fails and production is hampered in industries. Besides that, thermostat is used to select temperature which is not efficient because of erosion of metal and losing to strength of metal for successive using. Consequently, analog system loses its own linearity function since it is mechanically designed temperature control device.

The temperature can be controlled more efficiently using interface between temperature sensors LM35 which produce linear voltage signal with rising temperature and microcontroller which takes response fraction of millisecond to response. Microcontroller takes signal from temperature sensor and compare with pre-set value of temperature then take decision when heating device or cooling device would be turned on and the duration of maintained temperature in system.

The pseudo code for control the overall heating and cooling system can be written as:

When asking temperature > real-time temperature

Heating element $=1$ for (asking temperature +1 Degree Celsius)

Cooling element $=0$ for 1 minute

When asking temperature < real time temperature

Cooling element $=1$ for (real-time temperature -1 Degree Celsius)

Heating element $=0$ for 1 minute

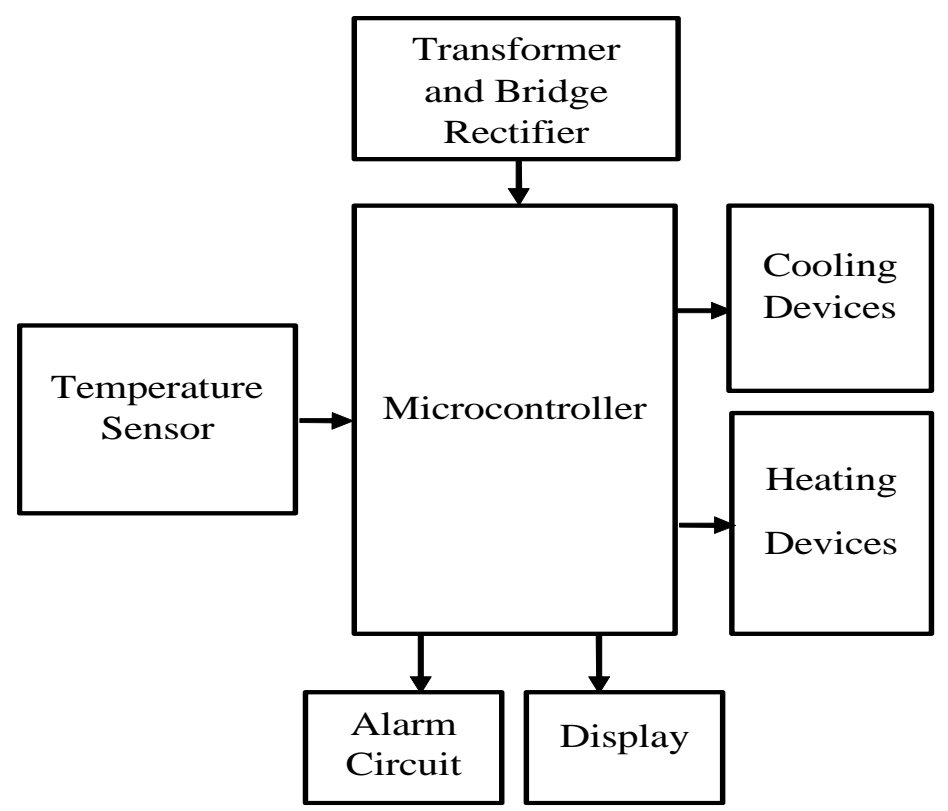

Figure 1. Block Diagram of Total System 
A buzzer is turned on when unexpected or large temperature is found in the system can be cause to damage industry. Figure 1 shows block diagram of total system.

\section{Temperature Measurement Precision}

The LM35 series of temperature sensors are manufactured by National Semiconductor Corporation and are rated to activate over a $-55^{\circ} \mathrm{C}$ to $150^{\circ} \mathrm{C}$ temperature range. These sensors do not need any peripheral calibration and the output voltage is proportional to the temperature. The scale factor for temperature to voltage conversion is $10 \mathrm{mV}$ per ${ }^{\circ} \mathrm{C}$. The LM35 series sensors come in different packages. The measurement of negative temperatures (below $0{ }^{\circ} \mathrm{C}$ ) needs a negative voltage source. However, this project does not use negative voltage source, and therefore would validate the use of sensor for determining temperatures above $0^{\circ} \mathrm{C}$ (up to $100^{\circ} \mathrm{C}$ ). The output voltage from the sensor is converted to a 10 bit digital number using the internal ADC of the PIC16F587A. Since the voltage to be measured by the $\mathrm{ADC}$ ranges from 0 to $1.0 \mathrm{~V}$, the $\mathrm{ADC}$ requires a lower reference voltage (instead of the supply voltage $\mathrm{Vdd}=5 \mathrm{~V}$ ) for $\mathrm{A} / \mathrm{D}$ conversion in order to get better accuracy. The lower reference voltage can be provided using a Zener diode, a resistor network, or sometime just simple diodes. Figure 2 shows an approximate $1.2 \mathrm{~V}$ reference voltage by connecting two diodes and a resistor in series across the supply voltage.

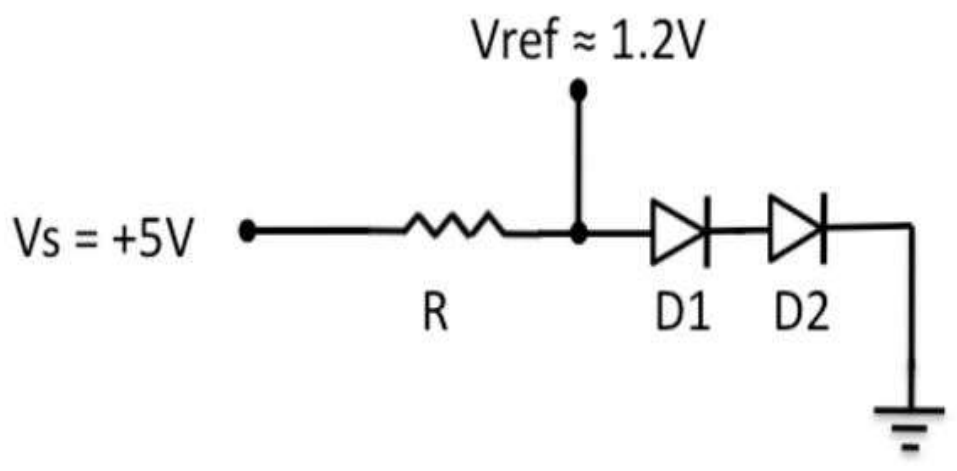

Figure 2. Block Diagram of Total System

The reference voltage Vref is $1.196 \mathrm{~V}$ 10-bit ADC maps a series of input voltage between 0 to 1023. The resolution of ADC can be expressed,

$$
\text { resolution }=\frac{1.196 \mathrm{~V}}{1024}=0.001168(\mathrm{~V} / \text { count })
$$

For example, when the surrounding temperature is $26.4{ }^{\circ} \mathrm{C}$. The sensor output is 264 $\mathrm{mV}(0.264 \mathrm{~V})$. The output of ADC is $0.264 / 0.001168=226$.

$$
C_{\text {temp }}=\frac{0.00168(\mathrm{~V} / \mathrm{count})}{0.01\left(\mathrm{~V} / \mathrm{o}^{\mathrm{C}}\right)}=26.4^{\circ} \mathrm{C}
$$

\section{Design of Temperature Control Circuits}

A $220 \mathrm{~V}$ AC supply is stepped down to $18 \mathrm{~V}$ by using potential transformer (TR1). Transformer (TR1) is connected with a bridge rectifier (BR1) to create pulse- setting 
DC where a capacitor (C1) is used to produce smooth DC. A heater coil (L1) is directly connected to power supply through relay (RL1), when relay "ON" heater would produce heat. Figure 3 shows the complete circuit diagram of industrial temperature control system.

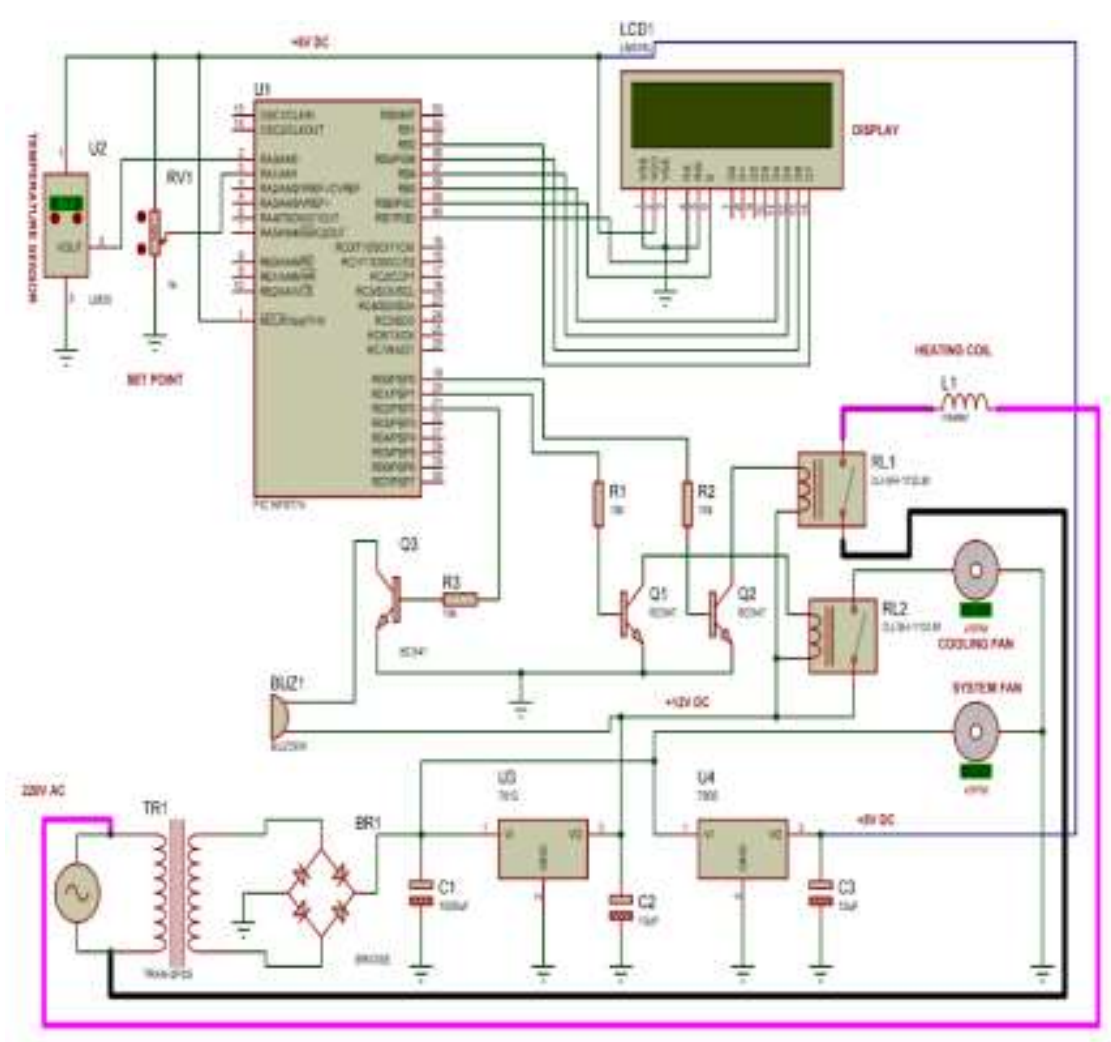

Figure 3. Complete Circuit Diagram of Temperature Control System

Two voltage regulators of 7412 and 7405 are used to get fixed DC voltages for different part of the circuit where U3 (7412) provides $12 \mathrm{~V}$ and U4 (7405) provides $5 \mathrm{~V}$. Furthermore, capacitor $\mathrm{C} 2$ and $\mathrm{C} 3$ are used to filter output signal in case of presence of any oscillation into the provided $\mathrm{DC}$ voltage.

The Buzzer (BUZ1) is connected with 12V DC voltage supply from U3 and the relays RL1 and RL2 are also connected with $12 \mathrm{~V}$ DC voltage supply from relays RL1 and RL2. The display (LCD1), microcontroller (U1), set point (RV1) and temperature sensor (U3) are connected with $5 \mathrm{~V}$ voltage DC voltage supply. In temperature controller there are two fans, one is system fan or circulating fan and another is cooling fan which are indicated in Figure 3. System fan is directly connected with $18 \mathrm{~V}$ and cooling fan is connected with RL2. When power is supplied to system fan is turned on whereas cooling fan is controlled by the relay (RL2). Microcontroller is connected directly with sensor (U2), set point (RV1) and display (LCD1). Microcontroller is also connected with Buzzer (BUZ1), relay (RL1) and relay (RL2) through a switching device (BJT) and a resistor. Common emitter configuration of transistor $(\mathrm{Q} 1, \mathrm{Q} 2$ and Q3) works as a switching device. Figure 4 shows that printed circuit board with installing all necessary equipment. 


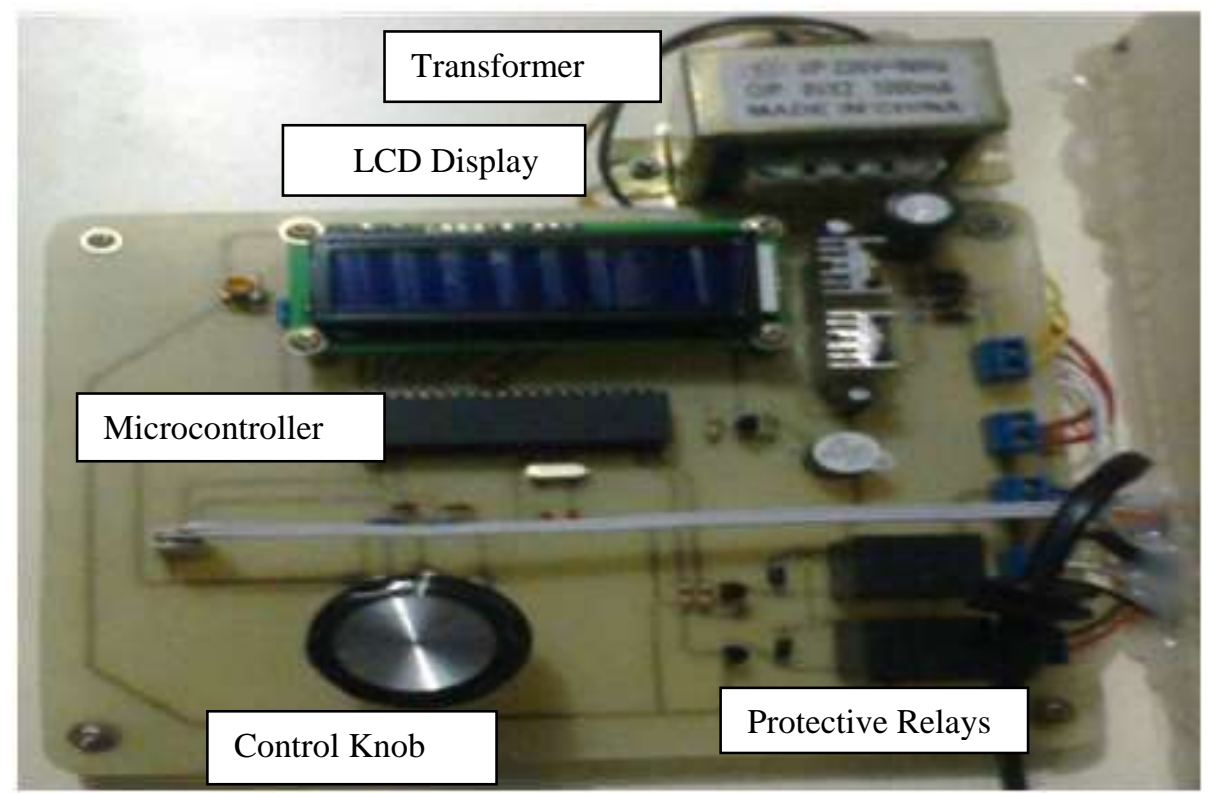

Figure 4. Printed Circuit Board to Total System

\section{Results and Discussion}

MicroC is used to compile microcontroller code in $\mathrm{C}$ language. For the hardware validation, normal tests have been carried by temperature measurement using LM35 and standard industrial thermometer which is shown in Figure 5. However, for controlling temperature testing, temperature is set to $40^{\circ} \mathrm{C}$ to experimental temperature control circuit. By varying control knob, temperature is set to $40^{\circ} \mathrm{C}$ which is to be maintained in the environment or it is called asking temperature. LM35 sensor sends voltage for corresponding temperature to microcontroller and microcontroller compare it with asking temperature. When asking temperature is greater than real time temperature of heater is turned on and cooling fan is turned off. Similarly, when asking temperature is less than the real time temperature heater is turned off while cooling fan is turned on. Table 1 shows that measurement of temperature and the corresponding status of heating and cooling elements.

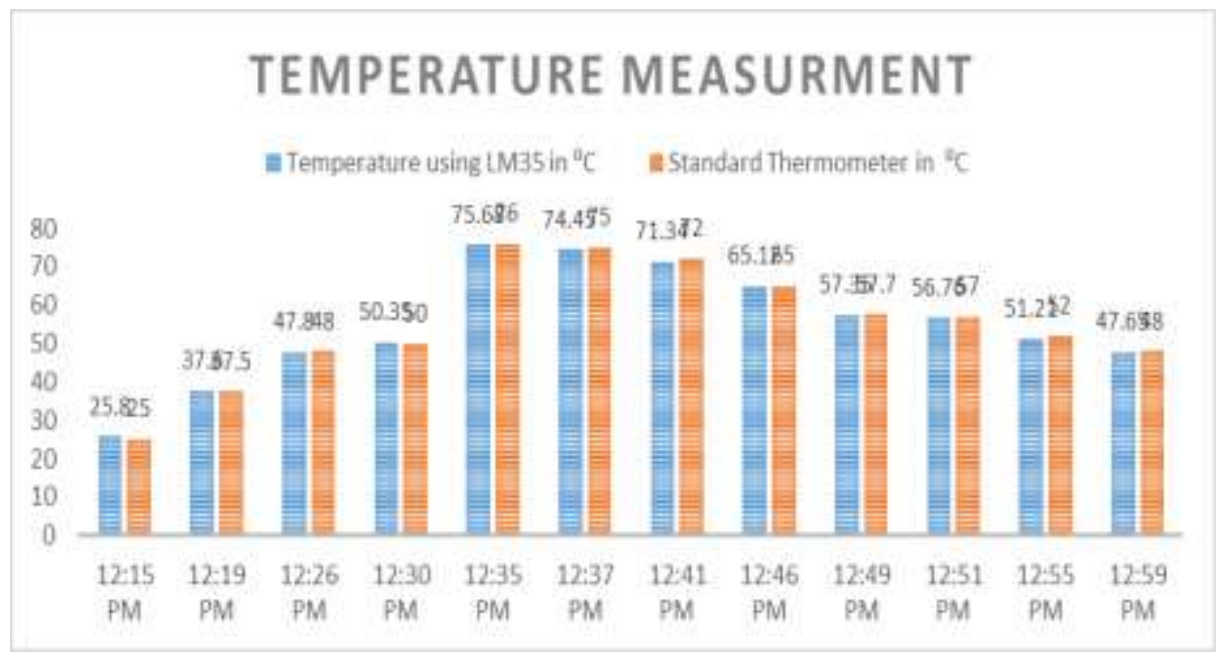

Figure 5. Temperature Measurement using LM35 and Standard Thermometer 
Table 1. Measurement of Temperature and Status of Heating and Cooling Elements

\begin{tabular}{|l|l|l|l|}
\hline Time & $\begin{array}{l}\text { Temperature using } \\
\text { LM35 in C }\end{array}$ & $\begin{array}{l}\text { Cooling } \\
\text { element status }\end{array}$ & $\begin{array}{l}\text { Heating element } \\
\text { status }\end{array}$ \\
\hline $2: 10$ PM & 25.8 & OFF & ON \\
\hline $2: 15$ PM & 30.6 & OFF & ON \\
\hline $2: 25$ PM & 41 & ON & OFF \\
\hline $2: 50$ PM & 39 & OFF & ON \\
\hline $2: 56$ PM & 41 & ON & OFF \\
\hline $3: 10$ PM & 39 & OFF & ON \\
\hline $3: 15$ PM & 41 & ON & OFF \\
\hline $3: 25$ PM & 39 & OFF & ON \\
\hline $3: 40$ PM & 41 & ON & OFF \\
\hline $3: 51$ PM & 39 & OFF & ON \\
\hline $3: 55$ PM & 41 & ON & OFF \\
\hline $3: 59$ PM & 39 & OFF & ON \\
\hline
\end{tabular}

To turn on and turn off the heater and cooling fan respectively, microcontroller passes the output voltage to the base of common emitter configuration transistor and transistor commences of current flow by means of switched on the heater or cooling fan. Since, the $40 \pm 1{ }^{\circ} \mathrm{C}$ of configuration temperature has been chosen to maintain in system, Figure 6 shows the temperature have been continued between $39{ }^{\circ} \mathrm{C}$ to 41 ${ }^{\circ} \mathrm{C}$.

On the contrary, when microcontroller passes zero voltage to transistor is turned off and heater or cooling fan is switched off. Due to carry large current to heater coil as well as cooling fan, relays are used as switches which are connected with collector of switching transistor. A range of temperature can be selected for maintaining at industry. Variable resistance is used to select the maximum and minimum responding time to the microcontroller. Buzzer is used as an audible alarm.

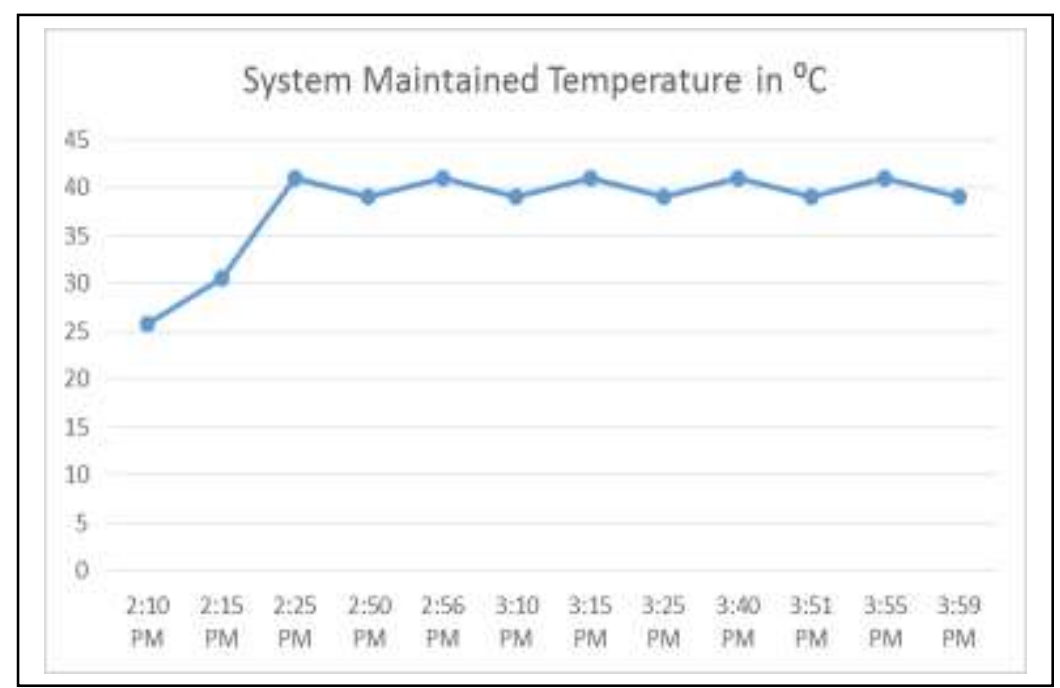

Figure 6. System Maintained Temperature using Microcontroller 


\section{Conclusion}

In this paper, microcontroller based temperature measurement and controlling system has been designed which contains few basic element having couple of lines control code using MicroC. This system measures temperature using LM35 temperature sensor device and compares the results with standard industrial thermometer value having negligible deviation. It is also able to keep maintaining laboratory temperature at constant level. The hardware validation shows that the temperature can be maintained between $39{ }^{\circ} \mathrm{C}$ to $41{ }^{\circ} \mathrm{C}$ which is displayed in LCD. In addition, a control knob has been used to set temperature according to application having a range of selection choice. Further investigation is required for getting precise temperature control in remote area application.

\section{Acknowledgments}

We thank University of Information Technology and Sciences (UITS), Dhaka1212 for infrastructure support and colleagues whose guidance on this study have helped to improve the presentation significantly and the contents of this paper.

\section{References}

[1] S. Bennett, "A History of Control Engineering", 1930-1955. London: Peter Peregrinus Ltd. On behalf of the Institution of Electrical Engineers. ISBN 0-86341-280-7, UK, (1992).

[2] W. Turner, "Introduction to industrial and systems engineering", Prentice Hall. ISBN 0-13-481789-3, USA, (1992).

[3] A. Goswami, T. Bezboruah and K. C. Sarma, "Design of an embedded system for monitoring and controlling temperature", Proceeding of International Conference on emerging technologies and applications in engineering, technology and science, Rajkot, Gujarat, India, vol. 1, (2008), pp. 105-110.

[4] J. Jayapandian and Usha Rani Ravi, "An Embedded Single Chip Temperature Controller Design", J. Instrum. Society, India, vol. 39, no. 1, (2006), pp. 50-54.

[5] L. Cai, "Temperature Measurement and Control System Based on Embedded Web", Computer and Information Science, vol. 2, no. 2, (2009).

[6] B. Levarda and C. Budaciu, "The Design of temperature Control System Using PIC 18F4620", Proceedings of ICSTC, (2010), pp. 282-286.

[7] M. R. Amin and R. B. Roy, "Design of microcontroller based Thyristor Controlled three-phase static volt-ampere reactive compensator", 2014 International Conference on In Informatics, Electronics \& Vision (ICIEV 2014), Dhaka, IEEE, (2014), pp. 1-6.

[8] M. R. Amin, M. K. Mishu, A. Al Faysal and M. R. Nizam, "Design and implementation of opto-isolator based low cost digital anemometer with wind direction monitoring system", 2016 5th International Conference on Informatics, Electronics and Vision (ICIEV 2016), Dhaka, IEEE, (2016), pp. 133-138.

[9] A. Goswami, T. Bezboruah and K. C. Sarma, "Design of an embedded and implementation of an Embedded system for monitoring and controlling the intensity of light", Proceedings of the 2008 International Conference on embedded systems and application, Las Vegas Nevada, USA, Vol.-ESA, (2008) July 14-17 pp. 117-123.

[10] Motorola, Inc., Phoenix, AZ, HC05 MCU LED Drive Techniques Using the MC68HC705J1A, Motorola Semiconductor Application Note AN1238, (1995).

[11] Motorola, Inc., Phoenix, AZ, Temperature Measurement and Display Using the MC68HC05B4 and the MC14489, Motorola Semiconductor Application Note AN431, (1999). 


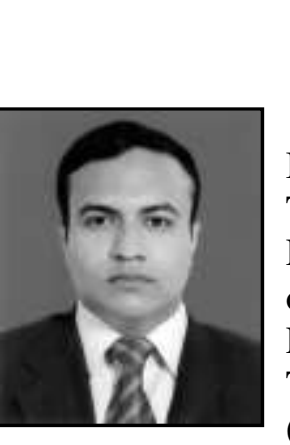

\begin{abstract}
Authors
Md Ruhul Amin, was born in 1989 in Rajshahi, he is a member of IEEE including society of IEEE Power Electronics and IEEE Transpiration Electrification. $\mathrm{He}$ is working as a Lecturer in the Department of Electrical and Electronic Engineering at the University of Information Technology \& Sciences (UITS), Dhaka, Bangladesh. Previously, he worked as a Graduate Research Assistant and Teaching Assistant, Faculty of Electrical and Electronic Engineering (FKEE), Universiti Tun Hussein Onn Malaysia (UTHM), Johor, Malaysia. He obtained his Master of Electrical Engineering degree from UTHM with fellowship award. He served as an organizing committee member for several project competitions in UITS and IEEE in Bangladesh. He supervised a number of undergraduate student projects which have been indexed in the IEEE digital library. He was also connected with IT firm as a senior consultant and former system engineer at Master Mind Computer, Dhaka. He participated in numerous volunteer activities in Bangladesh and Malaysia. Recently, he also served as a Chairman of Postgraduate Students Society in FKEE, UTHM. He has a number of publications in renowned journals including international conference proceedings in his area of expertise. His research area addresses the issues related to Power Electronics Applications and Control; Distributed Generation and Control; Electric Vehicles.
\end{abstract}

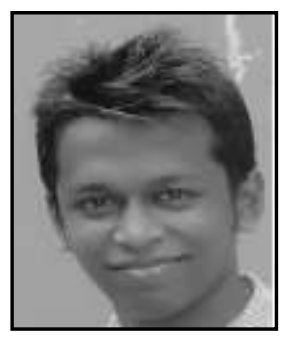

Ananda Ghosh, he is working as a Lecturer in the Department of Electrical and Electronic Engineering at the University of Information Technology \& Sciences (UITS), Dhaka, Bangladesh. He obtained his Bachelor of Electronics \& Telecommunication Engineering degree from University of Pune, India. His research area addresses the issues related to Telemedicine, Robotics, VLSI.

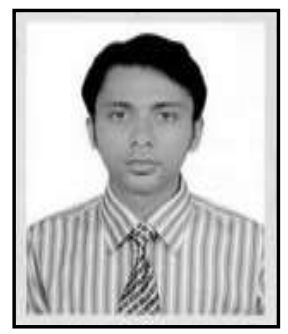

Abedul Hadi, he is working as a Lecturer in the Department of Electrical and Electronic Engineering at the University of Information Technology \& Sciences (UITS), Dhaka, Bangladesh. He obtained his BSc in Electrical and Electronic Engineering degree from American International University Bangladesh (AIUB), Dhaka. $\mathrm{He}$ also hold Masters of Business and Administration (MBA) degree from University of Dhaka (DU). Currently, he is pursuing MS in Renewable Energy Technology (MRET), DU. His research area addresses the issues related to Power Transmission and Distribution, Power System Analysis, Renewable Energy 